\title{
SUPERMAN: UMA SUPER MARCA TRANSMIDIÁTICA
}

Heitor Luiz Ribeiro Furtado

Faculdades Integradas Rio Branco

heitor.r.furtado@gmail.com

Daniel Moura Nogueira

PUC Rio - Departamento de Artes \& Design

daniel.m.nogueira@gmail.com

Resumo: Este artigo visa analisar a marca Superman através de sua trajetória, desde sua criação até os dias atuais. Investiga os motivos que possibilitaram que a marca tenha permanecido viva e relevante para seu público, bem como as razões da mesma ter se tornado ícone mundialmente reconhecido da cultura pop. Observa como foi sua trajetória transmidiática e, também, o seu Brand Equity, fundamentando-se nos conceitos de Phillip Kotler (2006), Joseph Campbell (2007) e em obras de Kevin Roberts (2005), David Aaker (2007), Grant Morrison (2012) e Larry Tye (2013). Como conclusão, apresenta fatores decisivos para a perpetuação da marca de forma potente e relevante através do tempo.

Palavras-chave: Superman, Marca, Transmídia, Brand Equity.

Abstract: This article aims to analyze the Superman brand through its history, from its creation to the present day. Investigates the reasons that enabled the brand to remain alive and relevant to its audience as well as the reasons to have become globally recognized icon of pop culture. Observes its transmedia path and also its brand equity, based on the concepts of Phillip Kotler (2006), Joseph Campbell (2007) and works by Kevin Roberts (2005), David Aaker (2007), Grant Morrison (2012) and Larry Tye (2013). In conclusion, it presents decisive factors in the perpetuation of power and relevance of the mark through time.

Keywords: Suparman, Brand, Transmedia, Brand Equity. 


\section{INTRODUÇÃO}

A marca Superman (Super-homem), propriedade da DC Comics, com pouco mais de 75 anos de existência, está em plena atividade e se enraizou na cultura pop e na memória afetiva de grande parte da humanidade através de diferentes culturas e gerações. Este artigo pretende analisar o processo de construção e evolução dessa marca, o qual permitiu que ela se tornasse uma das mais reconhecíveis em seu segmento, mesmo para aqueles que jamais leram uma história em quadrinhos de super-heróis (sua mídia de origem).

Cereais, camisas, brinquedos, jogos, dvds, blu-rays, filmes, seriados de tv e miríade de produtos de merchandising são distribuídos diariamente com a marca Superman. Ela ultrapassa em muito o seu suporte original, o gibi. A chancela da marca explora a força da conexão entre ela e seu público, construída ao longo das décadas.

$O$ vínculo das pessoas com a marca Superman vai muito além da mera diversão de infância:

Super-homem é o conto quase messiânico do filho único enviado dos céus pelo pai, para ajudar os mortais da Terra. Super-homem é o singular (e absolutamente distorcido) triângulo amoroso ambivalente entre o gentil Clark Kent lutando contra seu estonteante alter ego pelo coração de Lois Lane.... A criação persistente de dois adolescentes judeus de Cleveland, Ohio, na época da Depressão... e cada momento da interminável luta de Christopher Reeve para levantar-se e andar novamente. Super-homem me ensinou a ler, a gostar de arte e a sonhar. Até hoje, o ícone inspira as pessoas a voltar os olhos um pouco mais para cima... e observar o céu...(ROBERTS, 2005, p.5)

De acordo com TYE (2013, p.IX) “permanece íntimo para crianças de Boston a Belgrado e tem devotos adultos os quais, tais como estudiosos Talmúdicos, analisam cada expressão sua. E ele fez isso tudo com inocência e autoconfiança..." e, ainda, para CAMPBELL (2007, p.76) "quando a ação do herói coincide com a ação para a qual sua própria sociedade está pronta, ele parece seguir o ritmo do processo histórico.". Tudo isto demonstra um grande poder de adaptabilidade e conexão ao que Kevin Roberts chama de "emoção Número Um. A mais fundamental de todas...Amor" (ROBERTS, 2005, p.45).

\section{DESENVOLVIMENTO O INÍCIO DO PERSONAGEM}

Em abril de 1938, sob a tensão de eventos que desencadeariam a Segunda Guerra Mundial, pode-se dizer que havia um clamor por um herói e o timming foi perfeito. A imagem do Superman revelava um herói diferente de tudo que havia na época, mesmo ele sendo um amálgama de diversos outros heróis e figuras mitológicas que o precederam. Reinterpretando os argumentos do Übermensch de Friedrich Nietzsche, que foram utilizados e subvertidos por Adolf Hittler, Superman, com suas cores primárias e sua força descomunal indicava que as aventuras apresentadas na Action Comics No. 1, davam início a uma nova era do entretenimento de massa. 0 início da era de ouro dos quadrinhos.

Entender as demandas de para quem você está se comunicando, é fundamental no estabelecimento de uma relação duradoura. Segundo Kevin Roberts, em seu livro "Lovemarks": "É nos consumidores que você deveria estar prestando 
atenção. No que importa para eles. Caso contrário, você está se escondendo, e em apuros." (ROBERTS, 2005, p.35) Naquele exemplar, Superman dividiu o espaço com outras personagens, como Zatara, o mágico e Tex Thompson, mas os editores Jack Liebowitz e Harry Donenfeld perceberam, através de uma pesquisa com leitores, que cerca de $75 \%$ dos participantes tinham Superman como sua personagem favorita na revista.

O super-herói criado pelos jovens Jerry Siegel e Joe Shuster, fez as vendas da National Allied Publications alçarem vôo, muitos anos antes que sua personagem principal tivesse adquirido o poder de ir "Para o alto e avante". Suas vendas no primeiro número equivaleram a $64 \%$ do total produzido, proporcionando uma margem de lucro de $14 \%$ para a editora. No número 16 da publicação as vendas já alcançavam o patamar de $86 \%$ da tiragem produzida (TYE, 2013, p.37).

A parceria entre os garotos começara anos antes. Em 1932, criaram uma primeira versão, onde Super-man aparecia com um hífen e era um vilão que dominava a humanidade. Porém, ao final, percebia em uma crise de consciência, que se tivesse usado suas habilidades para o bem, seu nome teria seguido através da história como uma benção, ao invés de uma maldição. O fato dos criadores do Superman terem sido filhos de imigrantes judeus e de famílias muito pobres facilitou a comunhão de ideias com seu público, que era composto, em sua maioria, de garotos em idade escolar. É possível que, com esta história, ambos criadores tenham dado vazão à opressão que viviam em seu dia-a-dia. "The Reign of the Super-man" mostrava uma personagem ainda indecisa eticamente entre o bem e o mal, mas serviu como um começo para o herói que surgiria, com a evolução deste conto.

Anos depois, Jerry reescreveu e reestruturou sua personagem, dando a ela tudo aquilo que ele queria ser e ter: habilidades sobre-humanas, o amor de uma bela mulher e a vitória na luta contra os opressores e maléficos em prol dos menos favorecidos. Através da força da verdade da história por trás da personagem, essa nova versão trouxe a inspiração a Joe Shuster, que traçou então as primeiras linhas que definiram as fundações do visual da personagem e seu símbolo, o rudimentar escudo amarelo com um " $\mathrm{S}$ " vermelho em seu peito.

Um símbolo pode ser uma influência poderosa sobre a personalidade da marca, uma vez que pode ser controlado e possuir associações extremamente sólidas. A maçã mordida da Apple, o vaqueiro do Marlboro, o homem da Michelin e o homem dos consertos da Maytag podem criar e reforçar as personalidades de suas respectivas marcas. (AAKER, 2007, p.147)

Este é um aspecto de destaque sobre a marca Superman. Segundo Grant Morrison, escritor escocês premiado em 2007 pela série "All-Star Superman", em seu livro "Supergods":

Superman - despudoradamente especial, tão absolutamente individual que usava sua própria inicial como um distintivo - reafirmava a dignidade humana olhando a frente para um outro tempo. Shuster e Siegel tinham vislumbrado um futuro quando nós todos usaríamos nossos próprios emblemas orgulhosos de grandeza revelada e reconhecida, quando a tecnologia seria simplesmente uma ferramenta para nos ajudar a expressar a criatividade e a conectividade que eram o 
direito de nascença de nossos supereus dourados. (MORRISON, 2012, p.15)

Em janeiro de 1938, após muitas tentativas frustradas de fazer sua tirinha do Superman ser publicada em diversas editoras, as coisas mudaram para Jerry e Joe. Os novos donos da National Allied, (que futuramente se tornaria a DC Comics), Jack Liebowitz e Harry Donenfeld, com planos para o lançamento de uma nova revista chamada Action Comics, entraram em contato com Jerry e Joe e após acertarem as dívidas que o antigo dono tinha com a dupla, fecharam um contrato de US\$130,00 para a adaptação do material criado inicialmente para tirinhas de jornal, para um formato de revista de 13 páginas. Os jovens, recebendo o dobro por página do que normalmente eram pagos, aceitaram e assinaram o contrato que daria início a uma marca multibilionária. Ao fazerem isso, entretanto, estavam vendendo para seus contratantes os direitos de uso da sua personagem. Jack e Harry agora eram donos do Superman. Jerry e Joe tornaram-se apenas empregados, não importava que eles tivessem criado o super-herói.

Grant Morrison pondera:

Após todos aqueles anos, de começos falsos e frustrados e incontáveis rejeições, Siegel e Shuster tinham achado ouro. Naturalmente a coisa óbvia a ser feita seria vender todos os direitos para a National Comics... pela soma de US\$130,00. Sim. Pare por um momento e considere essa soma sob à luz da mega fortuna que Superman fez para seus mestres corporativos desde então. (MORRISON, 2012, p.12)

Este contrato definiu a base da relação entre criadores e as editoras. Até os dias de hoje, contratos agressivos sobre cessão total de direitos de uso são emitidos pelos departamentos jurídicos de editoras, em busca de oportunidades de novos produtos e novas marcas a serem exploradas. Jerry e Joe continuaram trabalhando durante anos e conseguiram colher em parte os louros de sua criação, sobretudo devido ao dano de imagem causado pelo extenso processo jurídico, que figurava a DC Comics como vilã para a opinião pública. Mas nunca mais tiveram o controle sobre ela, mesmo após diversas batalhas judiciais.

\section{TRANSIÇÃO DE MÍDIA}

A venda de direitos deu ao seus novos donos a oportunidade de explorar novos territórios com a marca. Em 12 de fevereiro de 1940, o primeiro episódio das Aventuras do Superman estreou pela rádio WOR em Nova York. Foi o início das aventuras do homem de aço através de outras mídias. Seu programa de rádio durou por cerca de uma década através de 2068 episódios que, com o patrocínio dos Cereais Kellogg's, levaram o Kryptoniano para os lares de famílias americanas.

É interessante ressaltar como a marca, que começava a construir sua identidade e se beneficiava agora dos talentos de escritores e artistas além de sua mídia original, precisou se adaptar às ondas do rádio, para se tornar crível aos ouvidos de sua audiência. O rádio, que deu ao Superman seu poder de voar e sua principal vulnerabilidade, a Kryptonita, deu a ele e a todas as personagens coadjuvantes que 0 cercavam, vozes, jargões e sons, necessários para representar essa marca na mídia em 
questão, que até hoje são usados como referência em novas representações do superherói.

O narrador, Jackson Beck anunciava: "Mais rápido do que uma bala, Mais forte que uma locomotiva. Capaz de saltar sobre prédios com um único salto!". Introdução logo seguida pelas famosas interjeições: “É um pássaro!”, “É um avião!” , “É o Superman!" e o narrador concluía: "Sim, é o Superman! Um estranho visitante de outro planeta, que veio para Terra com poderes e habilidades muito maiores que as de homens mortais. Superman, capaz de mudar o curso de grandes rios, entortar aço com as próprias mãos! E que, disfarçado como Clark Kent, um recatado repórter de um grande jornal metropolitano, trava uma batalha sem fim pela verdade, justiça e o sonho americano!". Tye diz que as últimas quatro palavras foram incluídas no verão de 1942, se tornando parte do lema da personagem e foram escolhidas por um psicólogo infantil para garantir que elas tocassem nos pontos certos de uma nação em guerra. "A ideia de um jeito americano distinto de crer e agir tomava conta da mente do público e da mitologia do Superman. Novamente, Superman estava refletindo e refratando sua era de uma forma que ajudou a defini-la". (TYE, 2013, p.90)

A marca Superman chegou a se colocar como uma arma contra o racismo e a intolerância racial pregada pela Ku klux Klan (KKK). No episódio de rádio "O Clã da Cruz Flamejante", Superman lutou contra a KKK e afetou o prestígio e a habilidade de recrutamento da organização, que revidou boicotando o patrocinador do programa. Contudo, com o enorme sucesso e audiência do episódio, a Kellogg's manteve o show no ar. A marca entrava, assim, para história se interligando à cultura popular e se tornando um símbolo de valores importantes para sociedade.

Essa evolução simbólica do herói, o coloca na posição de um poderoso veículo de mensagens para uma nova geração de consumidores. Contudo, como Joseph Campbell afirma:

Os símbolos são meros veículos de comunicação; não devem ser confundidos com o termo final, o ponto essencial a que se referem. Pouco importa o poder de atração que trazem consigo ou a impressão que podem causar; os símbolos permanecem como meros meios convenientes, adaptados às necessidades de compreensão". (CAMPBELL, 2007, p.230)

Neste ponto, a construção de uma imagem leve, colorida e bem-humorada no universo da marca Superman, pensada para o público infanto-juvenil, permitiu o estabelecimento claro desta distinção. Ao longo do tempo, o símbolo mudou a forma de seu escudo e o "S" se tornou mais icônico, representando imediatamente a personagem que o trazia no peito e uma série de outros valores que se uniram à sua mitologia, como paz e mais recentemente esperança.

Ainda com as revistas em quadrinhos em plena venda, impulsionada pelos programas de rádio, no início da década de 1940, os irmãos Max e Dave Fleischer foram contratados pela Paramount Studios pela quantia de US\$100.000,00 por episódio para criar a primeira interação animada da personagem. A trans mídia então ocorreu com os atores Bud Collyer (Superman/Clark Kent) e Joan Alexander (Lois Lane) reprisando seus papéis já tão difundidos na memória dos fãs. Essa coerência contribuiu para o estabelecimento da marca e aceitação dos curtas animados pelo público "Cerca 
de 20.000.000 de Supermaníacos mal podem esperar pelo desenho animado de dez minutos do Superman, que aparece uma vez por mês em mais de 7.000 cinemas americanos" Escreveu (a revista) Time em julho de 1942". (TYE, 2013, p.95)

O próximo passo, dez anos após sua estreia foi dar carne e osso para Superman. Desta vez a responsável foi a Columbia Pictures. O ator Kirk Alyn foi escolhido para o papel. Ele e seus produtores construíram sobre o que já havia sido feito nos quadrinhos e rádio, expandindo o universo da marca e respeitando seu público ao ponto de o nome de Kirk aparecer nos créditos apenas como Clark Kent. Superman era representado pelo próprio Superman. Mesmo os tons de cinza e as limitações da tecnologia da época não impediram que o público infantil se conectasse com a marca.

Em 1952, Superman migrava novamente para uma nova mídia, a televisão. 0 ator George Reeves, vestiu o uniforme e a marca do super-herói, em uma época em que as revistas em quadrinhos eram atacadas por parte da sociedade americana por exporem os jovens ao universo do crime, terror, horror e sexo e o rádio começava a entrar em declínio como meio de comunicação para as crianças. (TYE, 2013, p.132)

A série foi produzida até novembro de 1957 e deu aos fãs a oportunidade de ver pela primeira vez um Superman de carne, osso e cores. A partir de sua terceira temporada em 1955, a série já podia ser vista em cores pelos poucos proprietários de TV que tivesse esse recurso na época.

Séries de TV como Superboy (mostrando a juventude do Homem de Aço - no ar de 1988 à 1992), Lois \& Clark - As novas aventuras do Superman (no ar de 1993 a 1997) e paralelamente Superman: The animated Series (de 1996 a 2000) mantiveram a marca viva na televisão.

Nos quadrinhos, em 1986, logo após uma limpeza e organização editorial feita pela DC Comics em sua série de histórias "Crise nas Infinitas Terras", Superman passou por uma fase de reformulação onde teve seus poderes, limitações e história redefinidos por Jonh Byrne para torná-lo um herói mais atual para aquele tempo e facilitar a chegada de novos leitores, que já não conseguiam ver ordem ou lógica através da miríade de histórias lançadas desde o final da década de 1930.

Em 1993, o que começou como uma brincadeira entre os roteiristas e artistas da DC Comics, se tornou realidade. Superman finamente foi morto nos quadrinhos, salvando Metrópolis e o mundo do vilão apropriadamente chamado de "Doomsday" (Apocalipse no Brasil). Tudo parte de uma elaborada estratégia de gestão de marca, que fez com que o número 75 da revista do Superman vendesse em um dia mais de seis milhões de cópias e revitalizou a venda dos quadrinhos do herói que ressuscitou um ano após sua morte, renovado. Curiosamente, a década de 1990, registrou não apenas a morte do Superman, mas de seus criadores Jerry Siegel (1996) e Joe Shuster (1992). 


\section{BRAND EQUITY}

O Brand Equity ${ }^{1}$ da marca Superman vem sendo gerenciado ao longo dos anos formando com êxito os quatro ativos que servem como pilares para o acréscimo de valor da marca, segundo Aaker (2007,p.18):

1) Consciência do nome da marca;

2) qualidade percebida;

3) associações relativas à marca;

4) lealdade à marca.

A expansão através de diversas mídias, potencializou o desejo de consumo da marca devido a uma proposta de valor com credibilidade e consistência. De acordo com Aaker, "Consciência da marca é a presença de uma marca na mente dos consumidores... reconhecimento e lembrança são sinais de muito mais do que apenas a memorização de uma marca." (AAKER, 2007, p.98) E, ainda:

uma afirmação dos benefícios funcionais, emocionais e de autoexpressão oferecidos pela marca que proporcionam valor ao cliente. A proposta de valor efeciente deverá conduzir a um relacionamento marca-cliente e impulsionar as decisões de compra" (AAKER, 2007, p.98)

Isso explica, em parte, o entusiamo de Morisson:

Desde sua criação, Superman era tão reconhecível como Mickey Mouse, Charlie Chaplin ou Papai Noel. Ele era imediatamente intrigante, imediatamente vendável. Marcar agressivamente a personagem principal com sua própria inicial nunca havia sido feito antes e foi um golpe de mestre de conhecimento de marketing. Superman vestia seu próprio logo. Ele era sua própria t-shirt. Seu emblema era a bandeira de um país pessoal, e, como a Cruz Vermelha, ele era bem-vindo em qualquer lugar. (MORRISON, 2012, p.15)

Os produtos que levam o emblema do "S" são os mais diversos: roupas íntimas, celulares, óculos, brinquedos, camisetas, mochilas, montanha-russa em parque de diversão, bottons, imãs, chaveiros, jogos de vídeo-game (o primeiro lançado em 1978 seguindo o sucesso do filme do mesmo ano), dvds e blu-rays, seriados de TV, desenhos animados, filmes etc. Mas a marca se associa ainda através de comerciais, como no caso da montadora Hyundai, onde Superman corre junto com Batman e Flash para emprestar seus atributos aos carros da companhia, ou ainda no caso de product placement nos filmes e seriados. Enquanto o filme de 1978 com Christopher Reeve, lucrou cerca de US\$300.000.200,00 mundo afora, seus lucros foram ampliados com associações de marca como os cereais Cheerios ou ainda a questionável aparição/associação da Malboro (tendo em vista à percepção atual que temos sobre os malefícios do cigarro e sua influência especialmente nociva sobre o público jovem) dentre outras marcas em cenas do filme.

\footnotetext{
${ }^{1}$ Brand Equity é um termo de Marketing que se refere ao valor adicional que se atribui a algum produto ou serviço. Esse valor influencia na forma como o consumidor pensa, sente e age em relação à marca, assim como nos preços, na parcela de mercado e na lucratividade proporcionada pela marca à empresa. (KOTLER, 2006)
} 
Já no filme de 2013, "Man of Steel", que arrecadou cerca de US\$ $668.000 .000,00$ apenas com sua exibição nos cinemas pelo mundo, também ganhou, durante sua fase de produção, cerca de US\$ 170.000.000,00 em product placements, de acordo com matéria do jornal Independent.

Essas cifras indicam a alta qualidade percebida na marca. "A qualidade percebida situa-se habilmente no âmago daquilo que os clientes estão comprando e, neste sentido, é uma medida definitiva do impacto da identidade de uma marca". "Entre todas as associações com a marca, apenas a qualidade percebida demonstrou impulsionar o desempenho financeiro" e "está vinculada a outros aspectos da forma como a marca é percebida, e com frequência os impulsiona." (AAKER, 2007, p.27)

Mas o que seria exatamente que os clientes estariam comprando em essência da marca Superman? Quais seriam as associações relativas à ela? "A marca Superman vai mais fundo do que o escudo. Autêntica. Poderosa. Comprovada. A marca de um herói." Estas palavras, extraídas do Superman Brand Book desenvolvido pela empresa Little \& Company, apresentam um esforço feito em 2005 pela DC Comics, em função do lançamento do filme "Superman: Returns" com o objetivo de "assegurar que seu maior super-herói fosse uma marca bem definida, compreendida e respeitada pelos licenciados, lojistas e compradores."..."O livro de marca precisava demonstrar que a marca era muito maior do que o logotipo do Superman e, para se firmar como um condutor de produtos de alta qualidade alinhados com os atributos aspiracionais da marca, o livro precisava vibrar com qualidade e inspiração."(WHEELER, 2007, p.284) 0 livro de capa dura com 60 páginas apresenta ao leitor as palavras "indestrutível" em uma capa, mostrando as qualidades heróicas do Superman e os atributos que definem a marca, tais como "ele não precisa de sua capa para voar, apenas sua vontade" e "Inspirador" em uma contra-capa onde "o livro demonstra como a marca pode inspirar pessoas de todas as idades a serem super-heróis em suas próprias vidas." (WHEELER, 2007, p.284). Mike Schacherer, diretor de design da Little \& Company disse "Nossa meta é inspirar profissionais de marketing, designers e licenciados a incorporar as grandes ideias que estão por trás da marca Superman. Força, Invencibilidade, Coragem." (WHEELER, 2007, p.285). Dentre as mensagens contidas neste guia inspiracional uma delas mostra uma mulher determinada vestida com uma camiseta com o símbolo do " $\mathrm{S}$ " com a frase "Quando eu visto o Escudo-S, eu tenho o poder de ser eu mesma. O poder de controlar meu próprio destino. O poder de ser o meu melhor. O poder de fazer com que as coisas aconteçam." (WHEELER, 2007, p.285), uma polaroid com um menino com uma fantasia do herói com a frase "Costurado através do tecido de nossa cultura" e ainda, em "uma página dupla com imagens do passado e do presente de Superman, o texto diz: "Um herói dos tempos modernos, não importa quantas vezes esses tempos são reinventados"”" (WHEELER, 2007, p.285)

\section{A MARCA NOS DIAS DE HOJE}

Em 2009, após um retorno não muito bem aceito por uma nova geração de fãs e com o modesto retorno financeiro do filme "Superman Returns" de 2006, ficou claro que a imagem do Superman precisava ser atualizada para um público que vivenciou o terror causado pelo 11 de setembro. A Série de TV Smallville, lançada um mês após o atentado já demonstrava isso em sua canção tema: "Alguém me salve, eu não ligo para como você faça isso..." "Todos os meus sonhos estão no chão". Um herói que não 
cruzasse a linha final para defender aqueles que protegia, já não tinha o mesmo apelo. A Marca Superman sempre soube se adaptar e fez isso novamente em sua nova versão de 2013. Nesta iteração o símbolo "S" é resignificado como sendo o símbolo de "esperança". O filme traz cenas brutais de luta e tenta construir um dilema trágico onde Superman se vê forçado a cruzar, para o grande público ao menos, a linha que era necessária para se restabelecer como herói de uma época violenta: ele mata seu inimigo para proteger inocentes.

O roteirista do filme David S. Goyer tinha esperanças de redefinir Superman para o grande público, fazê-lo questionar quem era esse herói. Já o Diretor Zack Snyder pondera sobre a incerteza que essa decisão gerou na história da personagem e o que ela representa. Trouxe de volta o mistério,

O Mistério desencadeia a emoção. Soma-se à complexidade dos relacionamentos e das experiências. Manifesta-se nas histórias, nas metáforas e nos personagens icônicos que conferem textura a um relacionamento. $\mathrm{O}$ Mistério é fundamental para criar fidelidade além da razão. (ROBERTS, 2005, p.85)

No trailer mais recente da continuação deste filme de 2013 (Batman v Superman: A origem da justiça) as repercussões deste ato e da destruição causada pela luta entre o Super-herói e o Super-vilão, são exploradas. Em apenas 4 dias o vídeo teve mais de 18 milhões de visualizações na internet.

Para alguns, essa nova versão pode ter se distanciado da imagem já estabelecida da marca Superman, porém diversas características que a definem ainda estão lá. Fazer pequenas mudanças na aparência, poderes ou identidade secreta do Superman não afeta sua essência. Mesmo a infame fase do "Superman Azul Elétrico" não muda a natureza idealizada do Superman. O SUPERMAN existe em um estado de ser onde coisas são eternas, imutáveis, incorruptíveis e infinitas.

Escritores vem e vão, gerações de artistas deixam suas interpretações e
ainda assim algo persiste, algo que é sempre Superman. Nós temos que
nos adaptar às suas regras se quisermos entrar em seu mundo. Nós
nunca podemos mudá-lo demais, ou perdemos aquilo que ele é. Existe
um grupo persistente de características que definem Superman através
de décadas de vozes criativas e é aquela qualidade Superman-nesca
essencial, imperturbável que a personagem possui em cada encarnação
e esta é sua divindade, como quer que a chamemos. (MORRISON, 2012,
p.14)

Toda esta história, força e identificação formam e reforçam a lealdade à marca Superman e, de acordo com Aaker "lealdade da marca é uma consideração fundamental quando se atribui um valor a uma marca" (AAKER, 2007, p.31).

\section{CONCLUSÃO}

Através da análise dos acontecimentos presentes na história de construção da marca Superman, cuja identificação com o ser (super-)herói é instantânea, podemos perceber que sua capacidade de se adaptar e expandir para diversas mídias e suas posturas face aos fatos históricos, são fatores importantes em sua jornada evolutiva. 
Esta profusão de mídias estabeleceu uma grande quantidade de pontos de contato da marca com seu público, que ajudaram a fixá-la na mente de gerações e gerações.

Contudo, de pouco adiantaria este acesso à marca, se sua mensagem, seu propósito, não fossem cristalinos e não estivessem em sintonia com seus antigos e novos fãs. A marca Superman representa a esperança do bem. A certeza de que o bem pode vencer o mal e que estamos protegidos não apenas pela existência do superherói imaginário, mas sobretudo pelo ideal que ele representa em nós mesmos.

Ao se conectar com o que há de melhor em cada um de nós, a marca Superman, através de suas ações em diversas mídias e iterações, se esforçou para empregar e demonstrar a justiça e a bondade em suas ações. Contudo, tais conceitos são produtos da sociedade na qual a personagem está inserida, assim sendo, para manter a chama desse relacionamento de amor com seu público, mesmo este ícone da cultura pop, tem que constantemente se adaptar aos novos tempos e se renovar, sem contudo se afastar de sua essência.

Apenas através da vigília e ponderação constantes sobre o que seu novo e antigo público anseiam, é que é possível se manter nos corações e inspirações de bilhões e pessoas.

Esse cuidado e atenção com relação ao público, assim como a manutenção da sua verdade de forma coerente através de diversas mídias, são um exemplo a ser seguido por diversas outras marcas que podem realizar sua gestão inspiradas neste relacionamento que só faz crescer e se consolidar muito além do universo afetivo de seu público-alvo.

\section{REFERÊNCIAS}

AAKER, David. Construindo marcas fortes. Porto Alegre: Bookman Companhia Editora, 2007.

CAMPBELL, Joseph. O herói de mil faces. São Paulo: Pensamento, 2007.

FURTADO, Heitor. SUPERMAN: uma análise da construção, evolução e perpetuação de uma super marca. MBA em Branding - Gestão de Marcas. Rio de Janeiro: Faculdades Integradas Rio Branco, 2016.

KOTLER, Philip; KELLER, Kevin. Administração de Marketing. São Paulo: Pearson Prentice Hall, 2006.

MORRISON, Grant. Supergods. New York: Spiegel and Grau/Random House Publishing Book, 2012.

ROBERTS, Kevin. Lovemarks: O futuro além das marcas. São Paulo: M books, 2005

TYE, Larry. Superman: the high-flying history of America's most enduring hero. New York: Random House Publishing Book, 2013.

WHEELER, Alina. Design de identidade da marca. Porto Alegre: Bookman Companhia Editora, 2007. 